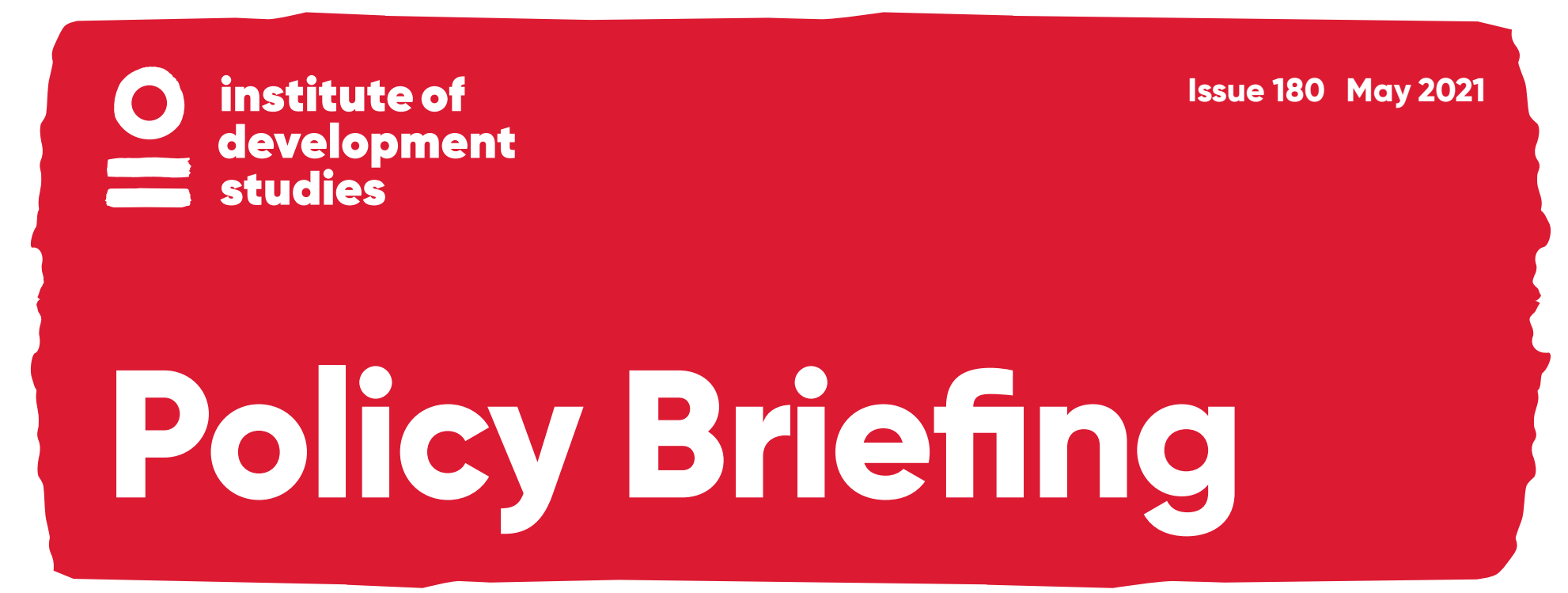

\title{
Imagined Futures: \\ Gaps in Support for Rural Youth in Côte d'Ivoire
}

Lack of employment opportunities for young people is a major concern across Africa, and involves many policy areas. In Côte d'Ivoire, the situation is challenging because of political and economic crises that have beset the country in recent decades, impacting negatively on education and accentuating job insecurity, particularly among rural youth. Tackling the problem in rural areas requires a youth-centred approach that builds long-term, welltargeted and coordinated interventions based on young people's lived experience.

\section{Key messages}

- Young people in rural Côte d'Ivoire aspire to financial stability and social standing within their communities. Despite gender inequalities, young men and women alike hope to acquire material possessions, such as houses and household items, as well as providing material support to extended families.

- Rural young people tend to be pragmatic about employment opportunities. Their plans reflect an intelligent assessment of the kind of income-generating activities they will need to pursue to support themselves and their families.

- Building on their knowledge, young people can be supported in gender-responsive ways to expand their participation in regional and global value chains by improving vocational training, access to affordable loans and cash transfers. 


\section{Challenges rural young people face}

Following the African Union 2009-18 decade for youth development, the African Capacity Building Foundation held a summit to identify innovative solutions to the persistent challenge of creating decent work across Africa. Four key suggestions highlighted the need for:

- Agricultural transformations to integrate small and medium-sized enterprises (SMEs) into regional and global value chains;

- Adding value through local agro-processing;

- Better access to investment capital for SMEs; and

- Changes in education to promote training for technical and vocational jobs.

These transformations require a youth-centred approach that builds long-term, welltargeted and coordinated interventions based on rural realities.

In Côte d'Ivoire, the issue of decent work is crucial, largely because of a recent history of political and economic conflict that has impacted negatively on education and increased job insecurity, especially among young people. The World Bank notes that 45.8 per cent of young people aged 15-34 were economically active in 2014, ranging from 28.1 per cent in urban areas to 64.8 per cent in rural areas.

The lower participation of urban young people in economic activities may explain why most interventions aimed at youth employment focus on urban areas. However, in 2014 only 11.1 per cent of the rural population had salaried work, while 88.9 per cent worked in small independent or family enterprises characterised by low productivity and underemployment. Over half the rural population lived below the national poverty line of 737 CFA francs (US\$1.23) per day in 2015 , underscoring the importance of better opportunities for decent work for rural young people.

This Policy Briefing is based on research in Côte d'Ivoire that explored the challenges and opportunities for rural youth employment, as part of a comparative research programme funded by the International Fund for Agricultural Development (IFAD). A mixed methodology was used to study young people's engagement with the rural economy, their aspirations for the future and the impact of education.

The research took place in Daloa, Soubré, Odienné and Korhogo regions and involved qualitative and participatory methods to explore both farm- and non-farm-related livelihood activities undertaken by young people aged 15-30. A small number of young women and men took photographs to illustrate their aspirations, which were the basis for discussions about the paths they sought to success. Group interviews and interviews with older adults offered insights into the context of young people's lives within each community.

This Policy Briefing presents rural young people's perspectives in three areas: (1) their imagined futures; (2) different employment opportunities; and (3) constraints on achieving their aspirations. We analyse data collected in the four regions in relation to the four key suggestions for creating work and better incomes outlined above.

\section{Imagined futures}

In our research sites, young people's vision of the future is a life with less poverty and precarity. Many already have significant responsibilities as spouses, parents and family providers. Their vision of the future is primarily rural or involves small towns with potential for off-farm income generation. Few dream of travelling further away.

Discussions revolved around what young people thought they might be capable of under different circumstances. Scenarios revealed much about gender inequality and the effect on young people of unforeseen events in their families. A 21-year-old married woman with two children, for example, would have liked to become a doctor. Had she been a boy, she would have been more likely to be 
enrolled in school. Young men who had to drop out of school because of poverty, loss of a parent or illness also spoke about the better occupations that education might have enabled or about migrating to Europe. However, common to all was a pragmatic view of what is required of them in their current circumstances and in the future.

Most families are involved in farming and some young people envision success as diversifying into new produce, such as cashew and other perennial crops. A 30-year-old male farmer from Odienné hoped to expand and modernise his farm by first acquiring more land and livestock, then using machinery and products for pest and disease control. He also considered the possibility of establishing an agroprocessing company. Ultimately, he dreamed of becoming an agricultural engineer. Young people who see themselves as farmers tend to endorse change to increase agricultural productivity, but their ideas are limited to smallholder farming rather than radical structural transformations.

For both young men and women, a brighter future is defined in terms of developing their own businesses, but their choice of crop or profession is typically gendered. Men aim to work as mechanics, masons or carpenters, or in electrical repairs, whereas young women want to sell food or women's clothing or to become hairdressers. Many associate off-farm activities with higher social status, but still imagine farming for their family's consumption, unless they move to a town or city. Their aspirations build on activities they already engage in - they are pragmatic and rarely dream of employing workers.

Most rural young people aspire to social success, which equates to financial stability, being able to ensure their families' wellbeing and achieving social standing within their communities. Success is marked by the acquisition of material goods, such as a house, but also refers to being able to assist members of their family. Success is also

\section{Rural young people plan income-generating activities based on pragmatic assessment of what they need to support themselves and their families.}

reflected in more pleasant living conditions, including owning their own vehicle and purchasing goods such as refrigerators or furniture.

\section{Employment opportunities}

Young people in rural Côte d'Ivoire engage in a variety of economic activities. They usually learn farming skills from an early age by working with their parents outside school hours and during holidays. These early skills are essential in later life. A 20-year-old woman from Korhogo explained how she began growing the same vegetables that her mother had grown before her, because this was something she already knew how to do. Young men also use skills learnt from their parents. A 22-year-old man from Soubré explained how he had learnt to farm yams and maize from working with his father, and okra and aubergines from working with his mother. Other young men had developed the skills to farm perennial commercial crops, such as cocoa, coffee, rubber, cashew or cotton.

Opportunities in farming are a mixture of unpaid family labour and working on one's own farm. Some young men take casual farm work for a few months, to earn additional income when their labour is not needed at home. Young women farm with their mothers, and once married, with husbands or mothersin-law. Young married women may have a small farm of their own or may do casual farm work if the family is very poor.

Most young farmers grow the same crops as their parents. But due to falling yields and fluctuating prices, there is less interest in expanding traditional commercial crops. 
Young men may turn to cashew or rice cultivation if they can access land, while young women may grow vegetables for the market. Occasionally, some adopt new varieties or cultivation methods. A 29-yearold man from Korhogo described how he was learning soil-less (hydroponic) tomatogrowing. A small number of young men engage in micro-commercial animal rearing to achieve higher returns.

Increasingly, young people are interested in off-farm income-generating activities, such as trading in commercial crops, commerce in local markets or trades such as sewing, hairdressing, carpentry, masonry, or working as motorbike or car mechanics. Young men enter the value chains of cocoa and cashew as farmgate buyers, as a 28-year-old man from Korhogo region explained:

When the cashew season begins, I go to small villages and hamlets to buy their cashew. Farmers phone me when they have cashew to sell. I work with a trader in Korhogo, who gives me the price of cashew nuts over the phone and when I have bought enough, he comes to buy them from me. When the cashew harvest finishes, I sell fertiliser and pesticides.

Young women entering value chains buy crops grown primarily by women, such as okra and peppers. Some young women process cassava to make attiéké, a main staple.

Otherwise, adding value consists primarily of preparing food to sell from stalls.

Interest in commerce is great among young men and women alike. However, as women have less access to land, they depend more

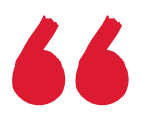

\section{Young men endorse} agricultural change, but their ideas are limited to smallholder farming rather than radical structural transformations. on off-farm activities. Two 28-year-old women from Daloa described a common trajectory. One wanted to go into business, but planned to start gradually and if she earned enough, to open a shop. The other was already a trader in lace and dresses. She hoped to open a shop in the market, but said this might not be achievable, at least in the medium term.

Finally, many young people combine farm and off-farm work. In Odienné region, young women and men work in artisanal goldmining. Young men across all sites engage in unskilled construction work, gradually acquiring skills in masonry, carpentry and decorating. Others, who were forced to stop their secondary education, enter artisanal apprenticeships, hoping to open workshops in the future.

\section{Constraints on achieving a decent life}

Regardless of region, most group discussions highlighted land scarcity as a serious problem, given that productive activities are predominantly agricultural. Our study indicates that the dynamics of land scarcity vary. In Daloa, the main cocoa-producing area until the 1980s, ageing cocoa fields are becoming less productive as soil becomes increasingly impoverished. Cocoa farmers are shifting to food production, but predominantly for subsistence. Their reduced capacity to generate income also reduces their capacity to provide employment for young people. In Soubré, a major production area for export crops, the sale of land by landowners has made it difficult for young men to obtain land to farm purely commercial crops and almost impossible for young women.

In Odienné and Korhogo, land tenure is more traditional and linked with lineage organisation. Where young people have access to land, terms of access are sometimes complicated and insecure. For a 28-year-old man from Korhogo, the land he cultivates with his older brother does not belong to either of them. Their father took custody of it when his brother died, because his brother's children were too young to farm it themselves. 
When their father dies, their cousins could claim the land for themselves.

Price-setting in the global market affects the viability of commercial crops in all four research sites. Even when they lose commercial value, farmers often continue farming these crops because they obtain valuable fertiliser and pesticides through buyer cooperatives and enterprises, which they then use for food crops. Young men are reluctant to cultivate crops with low returns, but they lack institutional support to diversify.

Generally, agro-processing is limited at village level, which presents a significant barrier, particularly to young women. Our data indicate that older women cultivate food crops and engage in different forms of commerce. Young women have few opportunities to learn agro-processing techniques, unless they stay with relatives involved in such work. Young people's opportunities for prospering in agriculture are therefore diminishing and support for non-farm income-generating activities is increasingly needed.

A major constraint is the size of most rural enterprises. Many are so small that they depend only on the owner, unpaid family labour or very few employees. So most young people rely on running their own micro-businesses. The most common strategy used by both young men and women to obtain start-up capital is to build savings by starting small, local, low-cost activities. Another strategy involves hoping that someone may give them capital. In the case of young women, their husband may provide the necessary money; and both young women and men may receive help from family members. Most are reluctant to take out a formal loan, fearing that they may be unable to repay it.

Young people's savings are limited and often subject to competing demands. A 30-year-old divorced woman from Daloa reported earning 190,000 CFA francs (US\$315) the first year she harvested cashew, but only 30,000 CFA francs (US\$50) in the third year because she fell ill. She struggled to invest in her business because

\section{Young women entering value chains focus on food crops; they have few opportunities to learn processing techniques in the village.}

she needed money for her mother's funeral and later for medical expenses. Competing demands can thus undermine incomegenerating plans and may hit young people harder because of caring responsibilities for young children and ageing parents.

Another constraint is the low level of education. Due to farm work, many children and young people are tired during lessons or do not have enough time to revise at home. Work may impact negatively on school performance, but lack of money for schooling is the principal reason for dropping out. However, work may also help to keep young people in school when it enables them to pay some of their educational expenses themselves.

There is evidence that those who have been in education longer are more likely to undertake informal vocational training or diversify into new income-generating activities. To develop a more vibrant rural economy, it is thus important to actively support school education and vocational training, especially for those at higher risk of dropping out.

Existing national programmes designed to facilitate access to employment have limitations. These programmes tend to focus on skills training, without recognising informal skills and knowledge that rural young people may have already acquired. Or they promote short-term microfinance schemes without considering that rural young people have multiple responsibilities that sometimes require trade-offs.

Similarly, transformations in the agricultural sector to integrate SMEs into regional and global value chains do not automatically create employment for young rural men and women.

\section{ids.ac.uk}




\section{Policy recommendations}

As access to land, labour and other resources is highly gendered and unequal, designing gender-responsive programmes is vital. These must ensure that both young women and men are provided with equal support to develop in lines of work that are perceived to be culturally appropriate, but with some space to challenge conventional norms.

- Crops, cultivation practices and potential for intensification must all be considered. Given increasing demand for rice, for example, the National Office for the Development of Rice Growing (ONDR) is piloting a project to develop the local value chain to increase production and create new off-farm jobs.

- The development of the rice value chain must consider how young men can be integrated at different levels. Our study shows that farmgate buying is the most common entry point into tree crop value chains for young men. They are unlikely to be able to create jobs for themselves and others elsewhere in value chains due to the small size of their enterprises and lack of capital.
- More investment is needed to develop vegetable and cassava value chains that predominantly employ women. Attiéké production remains low skilled and family based, but the value chain nevertheless creates possibilities for women to enter the commercial sector.

- To widen the scope of young women's participation, training in agro-processing techniques could be developed outside of the family, possibly by professionalising production to create jobs and reduce reliance on unpaid family labour.

- Access to capital must consider young people's concerns and responsibilities in relation to repaying loans. With around half the rural population living in poverty, cash transfers may be a better approach.

- More long-term vocational training is needed to create job and business opportunities. Our study shows that technical education and vocational training are important, but many existing programmes only offer short training courses on a limited set of skills. All those we spoke to who worked in a professional occupation and aspired to expand their businesses had been through informal apprenticeships.
Institute of Development Studies, Library Road, Brighton, BN1 9RE, United Kingdom +44 (0)1273 606261 ids.ac.uk

IDS is a charitable company limited by guarantee and registered in England. Charity Registration Number 306371. Charitable Company Number 877338.

\section{Further reading}

ACBF (2018) Tackling Africa's Youth Unemployment Challenge: Innovative Solutions from Think Tanks, Report of the 2018 Africa Think Tank Summit, Harare: African Capacity Building Foundation Christiaensen, L. and Premand, P. (2017) Cote d'Ivoire Jobs Diagnostic: Employment, Productivity, and Inclusion for Poverty Reduction [Vers de meilleurs emplois et l'inclusion productive: Emploi, Productivité et Inclusion pour Réduire la Pauvreté: Un diagnostic de la situation de l'emploi en Côte d'Ivoire],

Washington DC: World Bank [Groupe de la Banque Mondiale] INS (2015) Enquête sur le niveau de vie des ménages e Côte d'Ivoire (env 2015), Profil de pauvreté, Abidjan: Institut National de la Statistique

Mendez del Villar, P. et al. (2017) Analyse de la chaîne de manioc en Côte d'Ivoire, Rapport pour l'Union Européenne
This IDS Policy Briefing was written by Dorte Thorsen (IDS) and Affoué Philomène Koffi (Université Félix Houphouët-Boigny) and edited by Carol Smithyes (IDS). It was produced as part of the IFAD-funded research programme Challenges and Opportunities for Rural Youth Employment in Sub-Saharan Africa: A Mixed-Methods Study to Inform Policy and Programmes.

The opinions expressed are those of the authors and do not necessarily reflect the views or policies of IDS or IFAD.

(c) Institute of Development Studies 2021.

(i) (3) This is an Open Access briefing distributed under the terms of the Creative Commons Attribution Non Commercial 4.0 International licence (CC BY-NC), which permits use, distribution and reproduction in any medium, provided the original authors and source are credited, any modifications or adaptations are indicated, and the work is not used for commercial purposes.

ISSN 1479-974X

DOI: 10.19088/IDS.2021.041 